\title{
Children as Cosmopolitan Citizens: Reproducing and Challenging Cultural Hegemony
}

\author{
Markéta Supa \\ Vlastimil Nečas \\ Jana Rosenfeldová \\ Victoria Nainová \\ Charles University \\ Czech Republic
}

The article argues that, although digital and social media provide space and means for children's cosmopolitan citizenship, the tendency to reproduce cultural and ethnic stereotypes and prejudice prevalent in mainstream media can limit their capability and willingness to act and think as such. Drawing upon qualitative participatory research conducted with more than seventy children living in the Czech Republic, the article explores how children's media practice had a tendency to reproduce cultural hegemony. The paper ultimately argues that multicultural education and media education can together support children in reflecting on and challenging cultural hegemony, while at the same time potentially contribute to their transnational participation and cooperation with the use of digital and social media.

Keywords: Children, media practice, cultural hegemony, media education, multicultural education, cosmopolitan citizenship

From Media Practice to Cosmopolitan Citizenship
Sustaining and Contesting Cultural Hegemony
Research Design
Research Results
Discussion
Conclusion
References
Author Contact

Today's global society seems to be more connected than ever. Many parts of the world have been experiencing increased freedom of movement, exchange, and communication thanks to the blurring of physical as well as virtual borders. Media and digital technologies play an important role in this transnational connectivity and global consciousness. On one hand, children "access content, which transcends local, or even regional, physical, and cultural boundaries in their media experiences" (Lemish, 2015, p. 6). On the other hand, children themselves actively engage with other cultures. For example, through "self-directed cultural appropriation, as with much Western children's engagement with Japanese manga and anime" (Woodfall \& Zezulkova, 2019, p. 1), or with the use of social media for 
exploration, communication, participation, and/or action taking (Jenkins et al., 2016).

Yet, at the same time, the Western world is deepening some of the old and creating new societal divides. A number of national and international events that have taken place since the beginning of the 21st century seem to be reinforcing racist, xenophobic, and ultranationalist tendencies of numerous policymakers and the public. Media entertainment and news industries, political campaigns, and propaganda, as well as online public discourse, often contribute to national, cultural, ethnic, and religious prejudice, hostility, discrimination, racism, and white supremacy. For instance, Ahmed's and Matthes's (2017) meta-analysis of 345 worldwide studies published from 2000 to 2015 discovered mostly negative portrayal of Muslims and Islam in mainstream media since the attacks of September 11th, 2001, framing Muslims as religious extremists threatening "Western values."

In a divided world such as this, it seems more crucial than ever to explore and address the interconnectedness within cosmopolitan citizenship between multicultural education and media education in general. Based on a qualitative research study conducted with children 8-12 years old living in the Czech Republic, this paper explores how children challenge and/or reproduce ethnic and cultural stereotypes and prejudices that are prevalent in their local and global societal and media contexts. It then questions how and why this phenomenon should be addressed by multicultural and media education aiming not only at protecting but, above all, empowering children as cosmopolitan citizens.

\section{From Media Practice to Cosmopolitan Citizenship}

The majority of research on children's media practice, meaning their everyday media interactions, explores and aims to understand what children immediately do with, in, and through media (Storm-Mathisen, 2016). Knowing and understanding these media experiences is profoundly important to media education. Media education, generally said, aims at improving children's ability to access, critically understand, create, and share media content across diverse media platforms and with the use of varied technological tools (Buckingham et al., 2005). It is often suggested that it is the child's lived media experience that should guide varied educational interventions in media literacy (Woodfall \& Zezulkova, 2016). Although we agree with this suggestion, at the same time we question how this could be done if the aim is to address young children's future, rather than immediate, media practices.

For instance, it is reasonable to assume that the child will eventually engage with social media. This is why educational interventions worldwide address social media use of children before they reach the minimal required age for their own social media accounts, which is in most cases 13 years old. The aim is usually to prevent and protect children from potential online security, privacy, and cyber bullying threats (Livingstone \& Haddon, 2009). Yet, when not approached cautiously, this practice can turn into counterproductive discouragement, 
contributing and reinforcing media-related fears and anxieties (Zezulkova, 2015). For example, in Zezulkova's (2015) cross-cultural qualitative study, the young US and Czech children (ages 7-10) studied often spoke of Facebook as an evil platform, which brings misfortune to people and through which children get kidnapped.

Children's future use of social and digital media, however, does not entail only threats, but also opportunities such as the exercise of their rights, agency, voice, and power (Jenkins et al., 2016). Children and youth may use technology to gather and share ideas, network, mobilise, raise funds, communicate to the public, and lobby (Forbrig, 2005). While crossing artificial territorial boundaries, mediated children's and youth's geopolitical agency may further transcend their local and regional engagement into a form of global participation (Habashi \& Worley, 2014). A case in point is the FridaysForFuture international minor-led movement (since 2018), within which children and youth across 220 countries use social and digital media to organise school strikes demanding national governments to urgently address global warming and climate change. On Friday September $20^{\text {th }}, 2019$, more than 2,500 protests took place in 163 countries on seven continents with the estimate of more than 4 million people of all ages joining the global strike (Barclay \& Resnick, 2019).

The movement demonstrates that marginalised groups, to which children and youth also belong when it comes to political and civic participation, are capable and willing to actively participate as "makers and shapers" in global developments affecting not only their own but all lives (Cornwall \& Gaventa, 2001, p. 59). Wall (2019) defines this form of global civic participation as cosmopolitan citizenship. $\mathrm{He}$ argues that "[c]osmopolitan citizens participate in an international system of rights and responsibilities that promote shared human dignity and peaceful coexistence" (p. 8). According to him, cosmopolitanism must include respect for social and cultural differences, or as Held (2010) explains, recognise "each person as an autonomous moral agent entitled to equal dignity and consideration" (p. 15). Arguably then, living and learning in the social context of ethnic and cultural prejudice and hostility might influence children's capability and willingness to participate as active cosmopolitan citizens. Even though media literacy is considered to be a core competence for active and participatory citizenship (Mihailidis \& Thevenin, 2013), media education alone, therefore, cannot foster engaged cosmopolitan citizenship. The intersection between media education and multicultural education thus becomes crucial.

\section{Sustaining and Contesting Cultural Hegemony: From Protection to Empowerment}

In multicultural education, global citizenship (Carabain et al., 2012; Noddings, 2005) and cosmopolitan citizenship (Roxas et al., 2015; Todd, 2009) have emerged in recent years as possible perspectives on the future of multicultural education for the 21st century. The similarities, differences, and relations between the two concepts deserve greater discussion. Yet, for the 
purpose of this paper, we use cosmopolitan citizenship for its emphasis on respectful and peaceful coexistence, which aligns well with what Marino (2015) calls digital togetherness. Based on her 3-year online ethnography she argues that online "new media constitute spaces of digital togetherness, where diasporic experiences and transnational identities are constructed and negotiated" (p. 1). By using the concept of cosmopolitan citizenship rather than global citizenship, we wish to emphasize that the focus here is on transnational and intercultural social relationships and cooperation to which media education and multicultural education could together positively contribute.

Cosmopolitanism, however, is often approached in multicultural education as a "shallow" view of the world order, "privileged, and voluntary, blind as it is to questions of power and privilege" (Roxas et al., 2015, p. 233). Roxas et al. (2015) instead offer "deep cosmopolitanism" as an alternative that is "complicated, contextual, complex, and contested, with an understanding of how the dynamics of power and privilege play into cosmopolitanism" (p. 233). This is in agreement with others who suggest that multicultural education for cosmopolitan citizenship in a global age must confront cultural hegemony (Nieto, 2017).

Cultural hegemony can be understood as the maintenance of one culture's dominant power over others by promoting its worldviews and values as a universally valid cultural norm (Gramsci et al., 1971). Occasionally, the research speaks of white hegemony (Powell, 1996), while raising awareness about and questioning "a white-created and white-imposed racial hierarchy and continuum" in the Western world (Cobas et al., 2015, p. 1). Whereas it is generally agreed that media are pivotal in maintaining cultural (and especially white) hegemony (Nilsen \& Turner, in press; Doane, in press), some earlier studies suggested that using the Internet could challenge cultural hegemony partly by helping to eliminate stereotyping, prejudices, and discrimination (Glaser \& Kahn, 2005).

The results of more recent research show, however, that social media are not always successful in overcoming these tendencies (Awan, 2014; Cisneros \& Nakayama, 2015; Guo \& Harlow, 2014). Guo and Harlow (2014) stress in their study of YouTube videos that "citizens to a large extent use YouTube to perpetuate the same stereotypes found in the mainstream media, rather than use it as an alternative counter-public sphere" (p. 281). In a similar vein, Awan (2014) argues in a study analysing Twitter interactions that "online Islamophobia must be given the same level of attention as street-level Islamophobia" (p. 133). Tynes et al. (2015) reports on the still-growing racial discrimination among minority youth in the US on various social network sites and, according to Duggan (2017), one quarter of Black Americans "have been targeted online due to their race or ethnicity, compared with $10 \%$ of Hispanics and $3 \%$ of whites" (para. 1 ). The public thus tends to reproduce the inequalities of traditional media in social media environments instead of contesting the status quo.

In contrast, Anderson et al. (2018) illustrates how certain minorities in the US approach and praise social networks "as an especially important tool for their own political engagement" (para. 4). Youth account for one of the most politically active groups online (Holt et al., 2013; Neumayer \& Schossböck, 2011) who are 
also capable of using digital and social media to initiate and/or contribute to social change (Jenkins et al., 2016). Although less has been written about younger children's online civic engagement, the movement FridaysForFuture clearly demonstrates that even elementary school-aged children are willing and capable to participate. According to Lemish (2015), although children six to 11 years of age are "more prone and receptive to a host of exclusion practices, such as gender and race stereotyping, bullying, and victimization" (p. 46), they are also keen to explore the world and to engage in new social relationships.

Once children turn the required age (or possibly even before), social media will possibly become a space in which these young children will be making everyday decisions about how to engage and with whom. Their future use of digital and social media might be reproducing cultural hegemony and deepening the societal divide, or it can be challenging these entities and positively contributing to cosmopolitan citizenship. In order to nurture children's willingness to foster crosscultural social relationships and to think and act as cosmopolitan citizens, we argue that multicultural and media education practices should not only aim at protecting children. They, together, should also encourage children to engage in media practices that empower them and the others around them. Our research, introduced next, explores how children challenge and/or reproduce media and societal stereotypes and prejudice in their own media practice.

\section{Research Design}

The findings discussed here are based on partial findings from a larger study The Multicultural Life and Learning of Child Prosumers (2018-2021) exploring children's (age 8 to 12 years) perceptions of attitudes towards and relationships with people from diverse cultures in relation to media content that children both consume and produce. Specifically, this paper draws upon the results of 13 focus groups (FGs), each on average 45 minutes long conducted with 73 children (39 girls and 34 boys) in four elementary schools. The FGs were divided based on the children's ages into younger (8-10 years) and older (10-12 years) groups. These public schools were situated in varied geographical and sociodemographic areas of the Czech Republic, allowing us to effectively reach and include diverse children and engage with them in groups in their familiar environment.

Focus groups are increasingly common and highly recommended in research with children, although they must be well prepared and carefully designed, as we did by following Gibson's (2005) practical recommendations. The research also followed a number of internal and external ethical guidelines (Graham et al., 2013). These were to ensure participants' protection (including instructions on how to address sensitive topics that might emerge) and empowerment through participation (including instructions on how to offer diverse opportunities for each child to voice his/her opinion). Parents provided written informed consent and children gave oral informed consent. The FGs included a number of creative research techniques designed to stimulate discussion and invoke memory (Banks \& Zeitlyn, 2015), increase the children's involvement and enjoyment (Pyle, 2013), as well as to more sensitively, playfully, and indirectly 
explore topics that might have otherwise been difficult and/or uncomfortable for the children to discuss (Veale, 2005).

A creative technique called "casting agency and story making" was used to explore how children younger than 13 years old, who we should assume did not manage their own social media accounts at the time of our research, might challenge and/or reproduce media and societal stereotypes and prejudice when creating their own media content. During the creative intervention, the child participants were acting as casting agents and script writers. At first, each participant was given scissors and an A4 sheet of paper with a set of 24 portraits of actors and actresses of various ages, genders, ethnicities, and distinctive features (e.g., hair and beard styles, religious symbols such as veil or turban). Then an A1 coloured sheet of paper with a table including children's names on the left column and the general roles for actors/actresses in the top row (see Figure 1) were shown, explained, and then placed in front of the children. The general roles were based on Jung's (1936/1937/1959) archetypes as recommended by Berger and Zezulkova (2018) for media literacy interventions with children; these roles were Hero, Hero's Companion, Outlaw, Outlaw's Companion, Sage, and Jester.

Figure 1. The A1 Paper Sheet

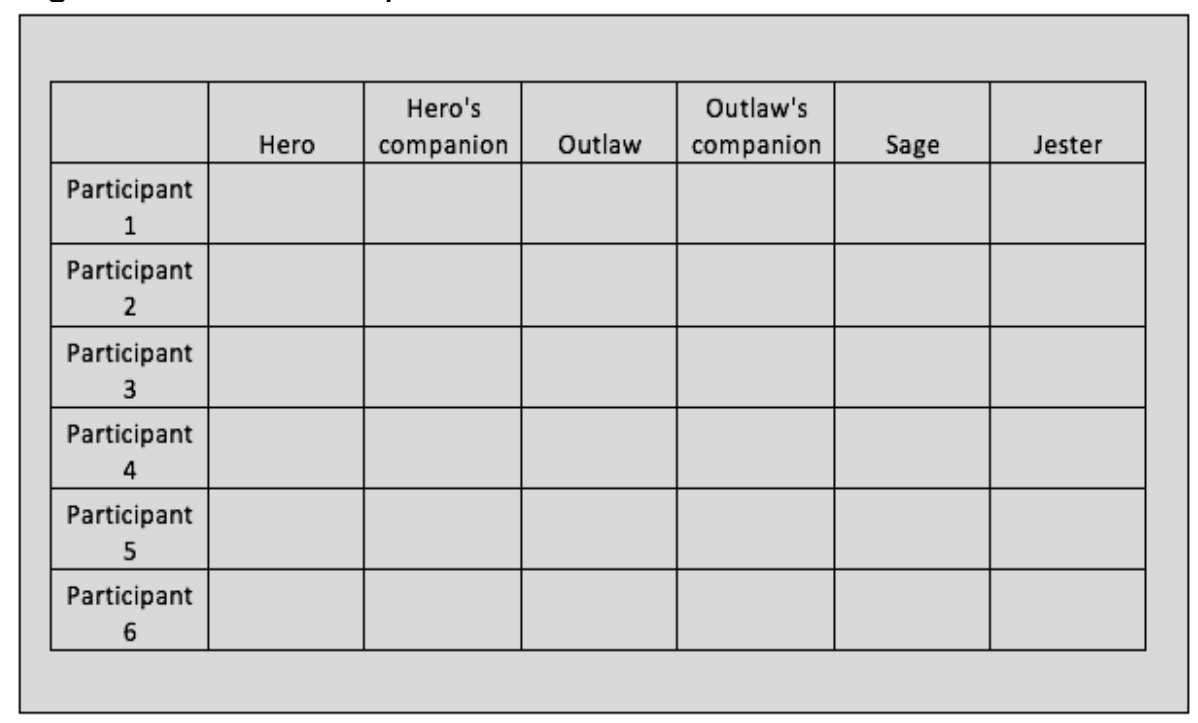

The children were asked to choose for each general role one of the actors and actresses from the A4 paper sheet and create a film or TV show plot. The children then worked individually, or sometimes in pairs, cutting out the actors/actresses from their sheet papers and handing them to a researcher who glued them to the table on the A1 paper sheet. All children selected the actors/actresses for the individual roles. Once the table was finished, the children shared one by one their casting choices and the plots that they had created. Some children created elaborate stories and explained their casting choices, while other children did not. Finally, the children were encouraged to look at the table as a whole and discuss anything that came to their minds when seeing the casting choices they all made. 
The audio and video recordings of the focus groups were transcribed, anonymised, openly coded, and thematically analysed. The direct citations used in the article were translated from Czech to English by the authors. The actors/actresses role selections were summed and ranked by overall frequency. For the purpose of this research, the individual actors' and actresses' ethnicities are described using British Identity Codes (ICs): Caucasian (IC1), Black African/Caribbean (IC3), South Asian (IC4), East/South-East Asian (IC5), and Middle Eastern/North African (IC6) (Steele et al., 2014). The following section discusses the three main themes that emerged from the casting agency and story making creative research technique applied during the FGs.

\section{Research Results}

1. The children chose ethnically diverse actors/actresses with age and gender imbalance to play in their family- and adult-oriented films.

One child hesitated at first to cast actors and actresses, explaining that she would need to talk to them before making a choice: "Well, I guess I would need the people to talk with me first, to have some communication with them" (girl, 11 years). The remaining participants made their casting choices based solely on the actors/actresses' visual portraits, which is in agreement with Brown et al.'s (2017) literature review suggesting that "children in early elementary school are particularly likely to focus on concrete, observable qualities rather than abstract attributes" (p. 66). All children then chose a mixture of ethnically diverse actors/actresses to play characters in their films.

Almost half of the participants chose one or two child actors/actresses to play the main characters and one participant created a film with almost all the characters (except the Jester) being played by children. As she explained,

A Journey to a Mysterious Island. [...] Because the children simply fell, went to the sea, to the ship and crashed there. Then they emerged on a mysterious island. [...] Because they are children and can fit there, more than adults, for example, they cannot fit. (girl, 8 years)

When the groups of children were shown their finished A4 tables, they pointed out that they had collectively chosen child characters and said they did not often see children play main roles in films and TV.

However, the stories that the children created were not intended purely for a child audience. They were mostly family-orientated adventure films, dramas, action films, and thrillers. Assuming there is a link between what they consume and create, the choice of genres would be in agreement with Chan et al. (2013) who suggest that children "are constantly consuming content that is not designed with them in mind" (p. 219). Moreover, the majority of main characters the children created were still played by adults, which is also consistent with Edström's (2018) findings that actors between 15 and 44 years old are most likely to be present in the media. 
In contrast, elderly persons are very unlikely to appear in the media (Edström, 2018). The participants chose the elderly characters mostly for the role of Sage, above all the elderly East/South-East Asian male with gray hair, gray beard, and glasses, and then the elderly darker-skinned Caucasian woman with dark hair and scarf tied under the chin (Table 1). These characters were perceived by the participants who chose them as "intelligent," "smart," and "experienced." Their choice of the Sage being elderly was in agreement with Jung's (1936/1937/1959) archetype of the wise old man or woman, which belongs together with the Hero among the historically most prominent archetypes (Oyserman et al., 2012).

Yet, while the male character was further called "professor like" and "similar to Einstein," the female character was often compared to a "witch" (explicitly to Baba Jaga) or a pythoness: "I have these two girlfriends who go somewhere for holidays, and they let this wise one, the lady, tell them their future" (girl, 13 years). The children thus partially reproduce negative media stereotypes about elderly people (Robinson \& Anderson, 2006) and contributed to the argument that the presence of older people in the media seem to be gendered (Edström, 2018).

A gender imbalance was additionally observable with the most frequently chosen actors and actresses (see Table 1 below). The main characters in the children's films were dominated by men (top 11 actors) rather than women (top three actresses). This imbalance occurred even though the child participants were of both genders and with slightly more girls, despite previous research that suggested girls tend to prioritise female characters (Zehnder \& Calvert, 2004). As Edström (2018) equally explored, men are more visible in media than women across all age groups and, as Appel and Weber (2017) discovered in their metaanalysis, women are underrepresented across diverse popular and news media genres. 
Table 1. The Children's Casting Choices (Most Frequent Selections Are in Grey)

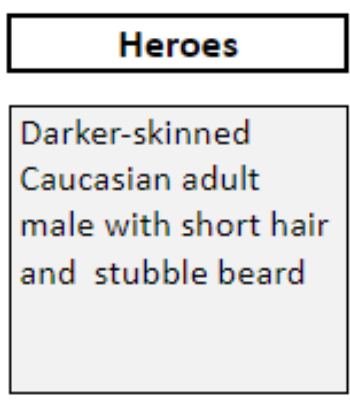

Caucasian adult male with mid long blond hair and bristle

East/South-East Asian adult female with light skin and long dark hair

Caucasian adult female with long blond hair
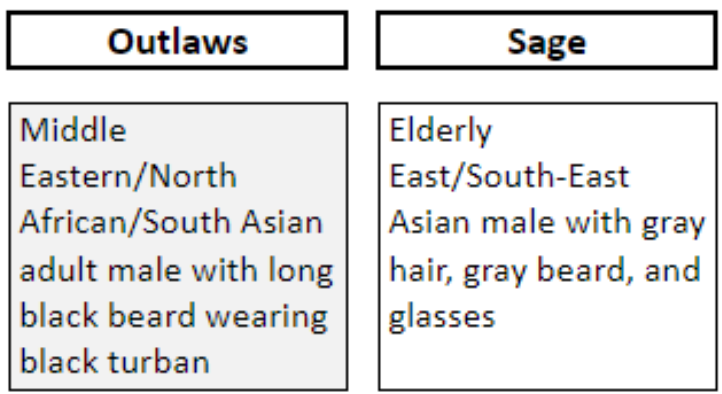

\section{Darker-skinned}

Caucasian (Roma

looking) adult male

with short hair and

goatee beard

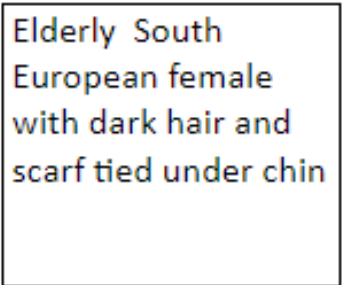

Black

African/Caribbean

adult male with

dreadlocks

\section{Elderly South \\ European woman \\ with dark hair and \\ scarf tied under chin

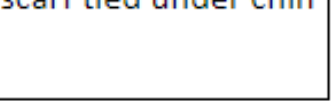

\section{Middle}

Eastern/North

African/South Asian

adult male with long

black beard wearing

black turban

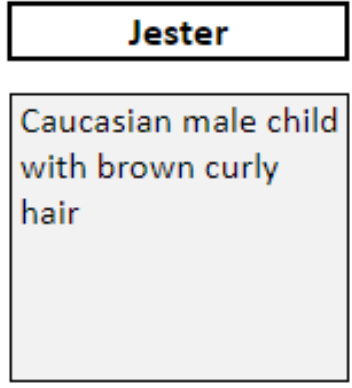

\section{Black}

African/Caribbean

male teen with

short hair

East/South-East

Asian male child

with short hair

East/South-East

Asian adult male

with short hair

2. The most frequently chosen actors/actresses to play positive characters were attractive Caucasian men described as masculine and then attractive Caucasian and non-White women described as feminine.

The darker-skinned Caucasian adult actor with short hair and stubble beard was chosen significantly more often than the other actors/actresses for the role of Hero. Some of the children who had chosen him as the Hero character compared him to "the one who sings Despacito," meaning the Puerto Rican singer Luis Fonsi. Important for the choice of this particular actor were, according to the participants, his look, which was described as fit ("thin," "muscular") and masculine ("tough," "rough"). He was also often described as a typical hero: "I chose this hero because he looks like a hero" (boy, 11 years) or "so, I had to choose this one, because he seems to be, like, typical, a typical main hero" (boy, 11 years). 
The participants chose the other Caucasian actors, usually for the Hero's Companion role (see Table 2 below), for the same reasons. This finding is consistent with Baker's and Raney's (2007) research, which discovered that superheroes in children's Western media are predominantly men, especially those portrayed as muscular and tough. Furthermore, the second most commonly chosen heroine was a Caucasian adult actress with long blond hair, which is also in agreement with research suggesting that superheroes are significantly more often Caucasian men and women (Baker \& Raney, 2007). The children themselves often argued they had chosen a concrete actor/actress based on his/her resemblance to an international or national singer (e.g., Beyonce, Ewa Farna, Karel Gott), a character from a foreign film (e.g., Fast and Furious, Jurassic Park), or from a local TV series (e.g., Surgery in the Rose Garden). This clearly shows that the children were reproducing the media overrepresentation of Caucasianlooking people as the main positive characters (Mastro, 2017).

However, the East/South-East Asian adult actress with light skin and long dark hair was the most commonly chosen actress for the heroine role. When this actress's ethnicity was pointed out, she was considered by the participants as Vietnamese or South Korean. Although US and adult-focused research repeatedly confirms that Asians are usually portrayed in popular media as "good" or "model" minorities (Ramasubramanian, 2007), we argue that, in this context, the local Czech culture and the children's global culture played a more substantial role. Firstly, Vietnamese are among the largest minority groups living in the Czech Republic and, although they remain significantly underrepresented in the Czech media, their general public perception is positive (Tuček, 2019). Secondly, recent studies show that South Korean popular culture is increasingly popular among children and youth from diverse places and backgrounds (Kim, 2016).

The East/South-East Asian adult actress was above all praised by the children for her attractiveness ("wow, she is beautiful," "she looks like a model") and positive socioemotional expression ("she looks kind," "she seems friendly"). The heroines were not put in roles conforming to gender stereotypes such as domesticity and passivity that are nowadays less common in media. Yet, their beauty and emotionality as the key feminine stereotypical characteristics of children's media heroines prevailed (Baker \& Raney, 2007).

Among the narratives the children created, two were about the Hero/Heroine characters facing racism. Interestingly, in both cases, the main Hero and Heroine were Black African/Caribbean. The actress was an adult with afrotextured hair and the actor was a teen with short hair (also often used as the Jester character). These were accompanied by other minority Sidekicks and bullied by Caucasian characters. In the first case, there was a narrative by a 12-year-old girl, who said that her

positive characters are actually this black woman [Heroine] and the Vietnamese woman [Heroine's Companion]. They live in America, or basically they live where these two White racist men live. The two main characters are also lesbians a bit. [...] The joker makes fun of them. And 
those two [Outlaw and Outlaw's Sidekick] are against them, they are against LGBT.

In the second case, an 11-year-old boy explained his chosen actors with the narrative,

They were all [all characters] at school. [...] They were laughing at them [Black African/Caribbean Hero and Middle Eastern/North African/South Asian male actor with long black beard wearing black turban as Hero's Companion] that they are Black. [...] The smart one [the elderly East/SouthEast Asian man as Sage] came and tried to help them."

3. The most frequently chosen actors to play negative characters were darkskinned minority men with distinctive visual features.

By far, the most commonly chosen actor to portray the Outlaw was the Middle Eastern/North African/South Asian actor with long black beard wearing black turban. Some of the participants, mostly the older ones who were 10-12 years old and who chose him, labelled him as a Muslim, Islamist, and/or terrorist. For instance, a 12-year-old girl said, "Here I have a typical Muslim," prompting a researcher to ask, "why do you think he's a Muslim?" To which the girl answered, while laughing and shrugging, "This is how they usually look like. As soon as I looked at him, I thought of the word bomb." Similarly, an 11-year-old boy said, "He is a Muslimist [children laughing] and he always throws a bomb when they [the good guys] have an advantage [children still laughing]."

Other participants were talking about the actor and his role as a terrorist. For example, a 12-year-old boy said, "this one, I'm sorry, he looks like a terrorist." The participants had chosen the veiled young female actress as Outlaw's Companion for the same reasons (see Table 2 below). Two 11-year-old boys working together explained their choice: "Then I chose those two terrorists. And these two, why not, right? (...) They look like racists, don't they? Racists. Like some Islamists, terrorists simply."

A number of participants who gave the actor with long black beard wearing black turban the Outlaw role said they chose him because he was a typical bad guy: "the bad guy, I think, he's like often like this" (boy, 10 years). Sometimes they compared him to a particular media character they had remembered. For example, he was compared to "the evil one from The Mummy, if he was shaved" (8-year-old boy); meaning the character looked like the secondary antagonist character Beni Gabor portrayed by Kevin J. O'Connor in the American action horror film The Mummy (1999).

This finding is in agreement with Ahmed's and Matthes's (2017) metaanalysis of the negative portrayal of Muslims in media mentioned earlier. It is also aligned with Brown et al.'s (2017) analysis of US children's prejudice towards Arab Muslims and Shaheen's (2003) argument that the perception, however, differs between Muslim men and women. In fact, the actor the children chose was a Sikh; 
this is in line with studies suggesting that Islamophobia can also affect nonMuslims, for example, Arabs, Sikhs, and South Asians (Zaal, 2012).

Table 2. The Companions and the Enemies

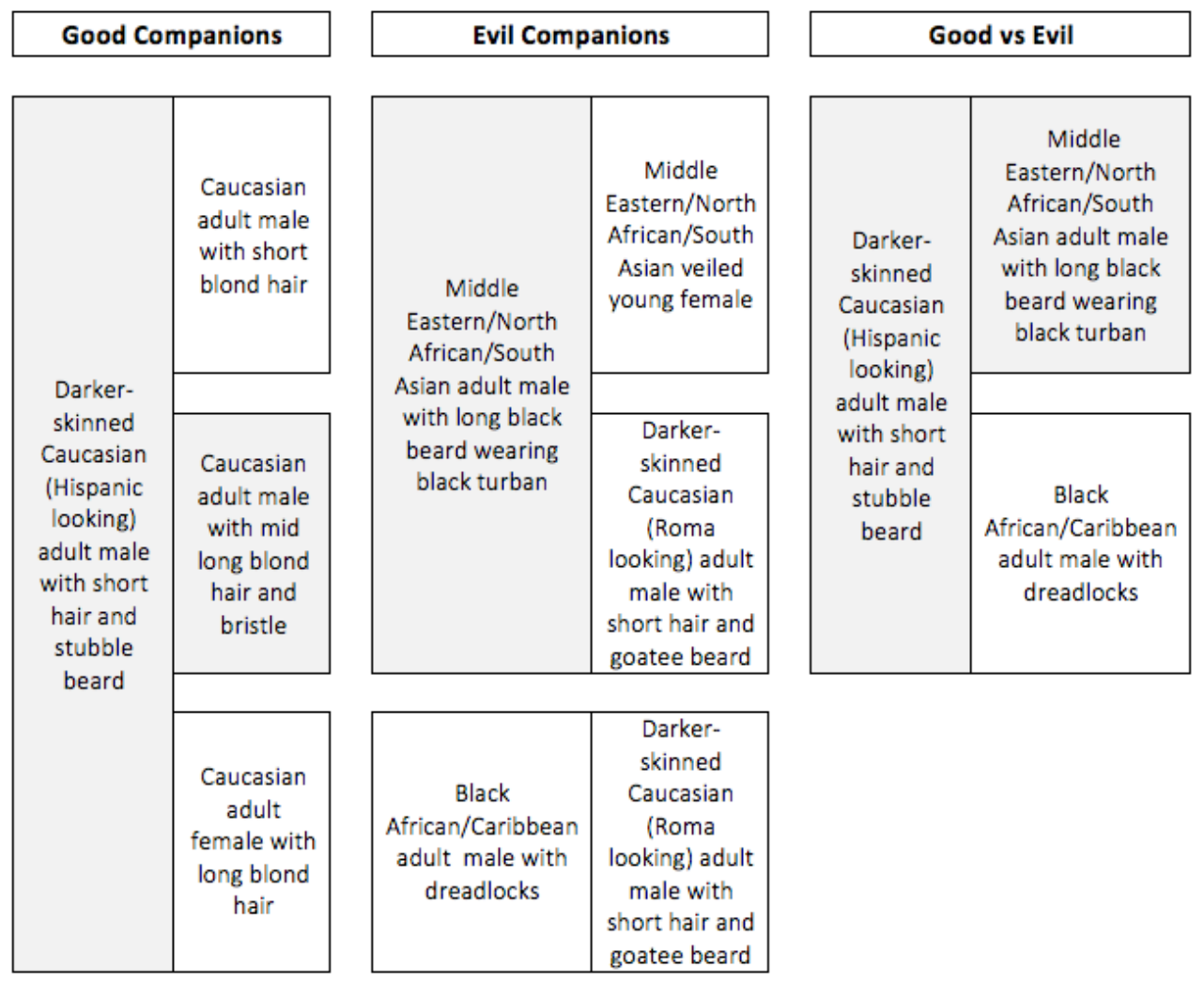

Many participants, especially the younger ones of 8 to 10 years old, who also chose the Middle Eastern/North African/South Asian actor as one of the two Outlaw characters, however, did not describe him, nor did they create stories with reference to his ethnicity, religion, culture, or terrorism. Rather, they described the character as "bullying," "beating" someone, trying "to destroy the world," wanting "to take over the planet," "grandpa" of another evil character, or someone who does some kind of fictional harm to Heroes. For example,

I have a Journey to Volcanokraine. [...] So the two [Heroes] are walking and suddenly it breaks under them and it falls down. [...] There will be volcanoes everywhere. And this was done by some evil man [Outlaw] and he fell there too. (boy, 8 years)

Nevertheless, many of the younger participants did not explain why they chose this character or they simply said, "I just chose him randomly." This suggests that the 
younger children's choice of the Middle Eastern/North African/South Asian actor to play the Outlaw role in their media narratives was possibly based on a less explicit basis when compared to the older children. As some studies suggest, children may develop racial attitudes and ethnic prejudice even before they classify the racial, ethnic, or cultural status of others (Hirschfeld, 1995; Quintana, 1998).

The other two commonly chosen actors to play the Outlaw were (1) a darker-skinned Caucasian (Roma-looking) adult male with short hair and a goatee beard and (2) a Black African/Caribbean adult male with dreadlocks. The first character often played the role of a gangster or a violent bully, but he was mostly a Sidekick to the main Outlaw characters (Table 2). The expectations for the Roma-looking actor to play a negative character was potentially influenced by the Czech media in which Roma people are both underrepresented and/or stereotypically and negatively portrayed (Sedláková, 2006). In general, the children did not spend much time explaining the choice of this character.

In contrast, the participants were quite outspoken about the Black African/Caribbean actor and his fictional character. He was given the role of a gangster, but also of a social outcast, who dropped out of school. Interestingly, even when this actor was assigned the role of a Hero, the Hero's Companion, or Sage, he was still often living at the edge of the law. The Black African/Caribbean actor was usually paired as both a Hero's Companion or an Outlaw with the Caucasian actors and characters. About both of them together an 8-year-old boy said: "These look like gangsters." Another 12-year-old-boy participant created a fictional story about them, where

this one will be a normal guy [darker-skinned Caucasian adult male with short hair and stubble beard] and then this friend of his [Black African/Caribbean adult male with dreadlocks] will come to him, ask him like if he wants to live some crazy life and so. [...] Like, by stealing expensive cars.

Even if the Black African/Caribbean adult male with dreadlocks was chosen as Sage in this 12-year-old boy's story, this character still was breaking the law: "Wise one is this man [Black African/Caribbean adult male with dreadlocks], and he has his garden. [...] He grows flowers there [laughing, possibly meaning marijuana]." The roles the participants assigned to, and the media narratives they created with, the Black African/Caribbean adult male with dreadlocks had some similarities with research that suggests that, in the US media discourse, African Americans are often portrayed as criminals who find themselves in difficult situations as a result of their own choices (Fabregat \& Kperogi, 2019; Hart, 2013; Willet \& Willet, 2013).

Nevertheless, it is important to note that the children's casting choices of negative characters seemed to be influenced by distinctive and possibly stereotypical features such as the Roma-looking actor's goatee beard, the Muslim considered actor's turban, the Muslim woman's veil, and the Black 
African/Caribbean actor's dreadlocks. The children did not tend to assign negative roles to actors and actresses who, while being dark-skinned, did not have any other ethnically, culturally, and/or religiously distinctive visual features. Instead, they were cast in diverse roles or not cast at all. Furthermore, when the children consciously focused on a single non-ethnic visual feature, this then usually surpassed the role of actors/actresses' ethnicity in their casting choices. For instance, the Sikh actor (the Middle Eastern/North African/South Asian male actor with long black beard wearing black turban) was occasionally chosen for the role of Sage, because "he has a long beard, so he looks clever," or the role of Jester, because "he has this kind of smile."

Brown et al. (2017) equally discovered that "skin color typifying someone from the Middle East was not enough to elicit negative stereotypes for elementary school-aged children" (p. 77). They argue that young children needed other visible markers such as hijabs to evoke stereotypes, prejudice, and/or hostility. Göle (2003) approaches these visible signs as stigmas because they transmit social information that may cause an individual or a group of people diverse social disadvantages and create obstacles to be accepted by society. He writes that it "is not the attribute as a thing in itself, such as a headscarf or a beard, that can be judged as creditable or discreditable - it is the normative cultural values and social relations of class and power that determine our perception" (Göle, 2003, p. 810).

\section{Discussion}

Digital and social media offer spaces and means for creating and sharing alternative narratives to those of entertainment media and news industries and, in doing so, challenge cultural hegemony. Research, however, suggests that people instead reproduce online the normative values and social relations of power and privilege (Holt et al., 2013; Vissers et al., 2012). Our qualitative participatory research conducted with more than seventy elementary school-aged children (812 years) living in the Czech Republic discovered ethnic and cultural bias, stereotypes, and prejudice in the children's own media practice. The main characters and narratives created had traces of gender imbalance (casting men over women) and gender stereotypes (men as strong and powerful, women as beautiful and socioemotional, minority men as more dangerous/threatening than more likable minority women). There was, in general, preference for standardized beauty and attractiveness emerging in the children's media practice. There seemed to be also acceptance of white hegemony (casting Caucasians for the positive Hero roles) and prejudice towards some ethnic minorities (especially Muslims, Black men, and Roma men).

We argued earlier that ethnic and cultural stereotypes and prejudice in children's immediate media experience may influence their future online and digital media practice relevant to cosmopolitan citizenship. More specifically, rather than contributing to respectful and peaceful coexistence and togetherness, these media practices could reinforce prejudice, hostility, discrimination, racism, and white supremacy. The question, therefore, is how media education and multicultural 
education can jointly address these issues and nurture children's cosmopolitan citizenship while facilitating their protection, as well as their empowerment.

Firstly, education towards cosmopolitan citizenship could benefit from the theoretical and practical approach of multicultural education to teaching even young children about privilege and power (Escayg, 2019). As Ramsey (2015) summarises, "[t]he purpose of multicultural education is to engage children in understanding and challenging the injustices that divide and diminish their world," which is why there has been an educational shift from superficial "portrayals and celebrations of diversity to deeper analyses of power and oppression and a need for radical social... change" (p. 6). This is equally important to the education of children as cosmopolitan citizens (Roxas et al., 2015) with rights and responsibilities to participate in, contribute to, and potentially shape coexistence and togetherness (Wall, 2019).

Secondly, cosmopolitan citizenship education could be enriched by media literacy interventions focused on both children's production and consumption of media content. When focusing on children's production, cosmopolitan citizenship education could draw upon media education's understanding of and experience in nurturing children's exercise of voice, agency, and power with the use of digital and social media (Jenkins et al., 2016). Media literacy is no longer only about analysis of media texts, but also about producing, sharing, and civically engaging (Mihailidis \& Thevenin, 2013). Yet, as Jenkins et al. (2020) emphasize, a necessary condition for civic engagement is civic imagination or "the capacity to imagine alternatives to current cultural, social, political, or economic conditions" ( $p$. $5)$.

When turning attention to children's consumption, children can be encouraged to explore, analyse, and reflect upon stereotypes, prejudice, bias, and white hegemony. For instance, Erba et al. (2019) designed and tested short-term and long-term effects of two types of media literacy intervention, aiming for the students to "hold more favorable attitudes toward Blacks and Latinos after having participated in a media literacy intervention" (p. 7). The first, critical media literacy intervention focused on mediated identity construction and its impact on our perception of the self and the others. The second, stereotypical media literacy intervention was built around the deconstruction of the "main stereotypical images associated with the main racial groups in the United States," while encouraging students to "think about the effects of such stereotypes on audiences" (p. 9). The results show that the stereotype media literacy intervention was more successful than the critical media literacy intervention in enhancing short-term and long-term favorable attitudes of university students toward members of racial minority groups.

At the same time, children's development should be taken into account because younger children's awareness and understanding of ethnicity and race might differ from older children's (Brown et al., 2017; Hirschfeld, 2008; Quintana et al., 2006). In addition, in order to draw upon children's complex media experience and its role in their perceptions of and attitudes toward relationships with ethnically and culturally diverse people in multicultural and media educational 
interventions, one should acknowledge that children might create, as well as consume, content not primarily intended for the children audience.

Even though this might be problematic as it contrasts adult ideas about innocent childhood and child appropriate media attitudes and behaviours (Woodfall \& Zezulkova 2016, 2019), we suggest that, with the shared aim of nurturing children's cosmopolitan citizenship, multicultural education together with media education can stimulate and motivate children's civic imagination about a different and better world and help them to see themselves as agents capable of making change instead of reproducing media and social bias, stereotypes, and prejudice. Based on this empirical research and theoretical framework, the research team has worked together with the Multicultural Centre in Prague to develop a pedagogical approach to education for children as media literate cosmopolitan citizens capable of transnational cooperation. The educational intervention in the form of a workshop series will be tested during the year 2021, if the global pandemic Covid-19 allows it.

\section{Conclusion}

Children are growing up and living in a world of increasing openness and connectivity across the borders, yet also in a world where social divides are still prevailing and, in some respects, even strengthening. Media education together with multicultural education can help children navigate their immediate and future lives in this world, as well as nurture their readiness and capacity to actively engage as cosmopolitan citizens. The qualitative participatory research conducted with the children living in the Czech Republic introduced in this article suggests that the reproduction of cultural hegemony in children's own media practices can be a potential obstacle to their cosmopolitan citizenship. It was thus argued that multicultural and media education could address and potentially improve children's global consciousness together with perceptions, attitudes towards, and relationships with people from diverse ethnic and cultural backgrounds. These fields of education can also together foster children's transnational connectivity and cooperation while allowing them to exercise their civic imagination, agency, voice, and capacity to engage in societal change. These goals are rather ambitious when it comes to multicultural or media education alone, but when both of them work together, these goals might be more realistic and achievable.

\section{References}

Ahmed, S., \& Matthes, J. (2017). Media representation of Muslims and Islam from 2000 to 2015: A meta-analysis. International Communication Gazette, 79(3), 219-244. https://doi.org/10.1177/1748048516656305.

Anderson, M., Toor, S., Rainie, L., \& Smith, A. (2018, July 11). Activism in the social media age. Retrieved from https://www. pewresearch.org/internet /2018/07/11/activism-in-the-social-media-age/. 
Appel, M., \& Weber, S. (2017). Do mass mediated stereotypes harm members of negatively stereotyped groups? A meta-analytical review on mediagenerated stereotype threat and stereotype lift. Communication Research, 48(2) 151-179. https://doi.org/10.1177/0093650217715543.

Awan, I. (2014). Islamophobia and Twitter: A typology of online hate against Muslims on social media. Policy \& Internet, 6(2), 133-150. https://doi.org/10.1002/1944-2866.POI364.

Baker, K., \& Raney, A. A. (2007). Equally super?: Gender-role stereotyping of superheroes in children's animated programs. Mass Communication \& Society, 10(1), 25-41. https://doi.org/10.1080/15205430709337003.

Banks, M., \& Zeitlyn, D. (2015). Visual methods in social research. SAGE.

Barclay, E., \& Resnick, B. (2019, September 22). How big was the global climate strike? 4 million people, activists estimate. Retrieved from https://www.vox.com/energy-and-environment/2019/9/20/20876143/ climate-strike-2019-september-20-crowd-estimate

Berger, R., \& Zezulkova, M. (2018). A remaking pedagogy: Adaptation and archetypes in the child's multimodal reading and writing. Education 3-13, 46(1), 64-75. https://doi.org/10.1080/03004279.2016.1178316.

Brown, C. S., Ali, H., Stone, E. A., \& Jewell, J. A. (2017). US children's stereotypes and prejudicial attitudes toward Arab Muslims. Analyses of Social Issues and Public Policy, 17(1), 60-83. https://doi.org/10.1111/asap.12129.

Buckingham, D., Banaji, S., Carr, D., Cranmer, S., \& Willett, R. (2005). The media literacy of children and young people. Ofcom

Buckingham, D., \& De Block, L. (2007). Global children, global media: Migration, media and childhood. Springer.

Carabain, C., Keulemans, S., van Gent, M., \& Spitz, G. (2012). Global citizenship public support for participation. NCDO Press.

Chan, K. W., Lemish, D., McMillin, D., \& Parameswaran, R. (2013). Beyond 'the west to the rest': A roundtable on global children's media flows. Interactions: Studies in Communication and Culture. 4(3), 211-220. https://doi.org/10.1386/iscc.4.3.211_7.

Cisneros, J. D., Nakayama, T. (2015). New media, old racisms: Twitter, Miss America, and cultural logics of race. Journal of International and Intercultural Communication, 8(2), 108-127. https://doi.org/10.1080/17513057.2015.1025328.

Cobas, J. A., Duany, J., \& Feagin, J. R. (2015). How the United States racializes Latinos: White hegemony and its consequences. Routledge.

Cornwall, A., \& Gaventa, J. (2000). From users and choosers to makers and Shapers: Repositioning participation in social policy. IDS Bulletin, 31(4), 5062. https://doi.org/10.1111/j.1759-5436.2000.mp31004006.x. 
Doane, W. (in press). Theorizing White Nationalism: Past, Present, and Future. In S. D. Nielsen \& S. E. Turner (Eds.), White Supremacy and the American Media. Routledge.

Duggan, M. (2017, July 25). 1 in 4 black Americans have faced online harassment because of their race or ethnicity. Retrieved from https://www.pewresearch.org/fact-tank/2017/07/25/1-in-4-blackamericans-have-faced-online-harassment-because-of-their-race-orethnicity/.

Edström, M. (2018). Visibility patterns of gendered ageism in the media buzz: A study of the representation of gender and age over three decades. Feminist Media Studies, 18(1), 77-93. https://doi.org/10.1080/ 14680777.2018.1409989.

Erba, J., Chen, Y., \& Kang, H. (2019). Using media literacy to counter stereotypical images of Blacks and Latinos at a predominantly white university. Howard Journal of Communications, 30(1), 1-22. https://doi.org/10.1080/ 10646175.2018.1423652.

Escayg, K. A. (2019). "Who's got the power?": A critical examination of the antibias curriculum. International Journal of Child Care and Education Policy. 13(1), 1-18. https://doi.org/10.1186/s40723-019-0062-9.

Fabregat, E., \& Kperogi, F. A. (2019). White norm, Black deviation: Class, race, and resistance in America's "postracial" media discourse. Howard Journal of Communications, 30(3), 265-283. https://doi.org/10.1080/ 10646175.2018.1491433.

Forbrig, J. (Ed.). (2005). Revisiting Youth Political Participation: Challenges for Research and Democratic Practice in Europe. Council of Europe

Gibson, F. (2007). Conducting focus groups with children and young people: strategies for success. Journal of research in nursing, 12(5), 473-483. https://doi.org/10.1177/1744987107079791.

Glaser, J., \& Kahn, K. B. (2005). Prejudice and discrimination and the Internet. In Y. Amichai-Hamburger (Ed.), The social psychology of the Internet. Oxford University Press.

Göle, N. (2003). The voluntary adoption of Islamic stigma symbols. Social Research: An International Quarterly, 70(3), 809-828.

Graham, A., Powell, M. A., Anderson, D., Fitzgerald, R., \& Taylor, N. J. (2013). Ethical research involving children. UNICEF Office of Research-Innocenti.

Gramsci, A., Hoare, Q., \& Nowell-Smith, G. (1971). Selections from the prison notebooks of Antonio Gramsci. International Publishers.

Guo, L., \& Harlow, S. (2014). User-generated racism: An analysis of stereotypes of African Americans, Latinos, and Asians in YouTube Videos. Howard Journal of Communications, 25(3), 281-302. https://doi.org/10.1080/10646175.2014.925413. 
Habashi, J., \& Worley, J. A. (2014). Children's projected political preference: transcending local politics. Children's Geographies, 12(2), 205-218. https://doi.org/10.1080/14733285.2013.812306.

Hart, W. (2013). Dead Black man, just walking. In G. Yancy \& J. Jones (Eds.), Pursuing Trayvon Martin. Historical contexts and contemporary manifestation of racial dynamics (pp. 91-101). Lexington Books.

Held, D. (2010). Cosmopolitanism: Ideals and realities. Polity.

Hirschfeld, L. A. (1995). The inheritability of identity: Children's understanding of the cultural biology of race. Child Development, 66(5), 1418-1437. https://doi.org/10.1111/j.1467-8624.1995.tb00943.x.

Hirschfeld, L. A. (2008). Children's developing conceptions of race. In S. M. Quintana \& C. McKown (Eds.), Handbook of race, racism, and the developing child (pp. 37-54). John Wiley \& Sons Inc.

Holt, K., Shehata, A., Strömbäck, J., \& Ljungberg, E. (2013). Age and the effects of news media attention and social media use on political interest and participation: Do social media function as leveller? European Journal of Communication, 28(1), 19-34. https://doi.org/10.1177/0267323112465369.

Jenkins, H., Shresthova, S., Gamber-Thompson, L., Kligler-Vilenchik, N., \& Zimmerman, A. (2016). By any media necessary: The new youth activism (Vol. 3). NYU Press.

Jenkins, H., Peters-Lazaro, G., \& Shresthova, S. (Eds.). (2020). Popular culture and the civic imagination: case studies of creative social change. NYU Press.

Jung, C. G. (1936/1937/1959). The archetypes and the collective unconscious. Routledge.

Kim, G. M. (2016). Transcultural digital literacies: Cross-border connections and self-representations in an online forum. Reading Research Quarterly, 51(2), 199-219. https://doi.org/10.1002/rrq.131.

Lemish, D. (2015). Children and media: A global perspective. John Wiley \& Sons.

Livingstone, S., \& Haddon, L. (2009). EU kids online: Final report. Retrieved from https://eucpn.org/document/eu-kids-online-final-report.

Marino, S. (2015). Making space, making place: Digital togetherness and the redefinition of migrant identities online. Social Media + Society. https://doi.org/10.1177/2056305115622479.

Mastro, D. (2017, September 26). Race and ethnicity in US media content and effects. Oxford Research Encyclopedia of Communication. Retrieved 12 Jan. 2021, from https://oxfordre.com/communication/view/10.1093/ acrefore/9780190228613.001.0001/acrefore-9780190228613-e-122. 
Mihailidis, P., \& Thevenin, B. (2013). Media literacy as a core competency for engaged citizenship in participatory democracy. American Behavioral Scientist, 57(11), 1611-1622. https://doi.org/10.1177/0002764213489015.

Neumayer, C., \& Schossböck, J. (2011). Political lurkers? Young people in Austria and their political life worlds online. In P. Peter, M. J. Kripp, \& E. Noealla (Eds.), CeDEM11 Proceedings of the International Conference for EDemocracy and Open Government (pp. 131-143). Edition DonauUniversität Krems.

Nielsen, S. D., \& Turner, S. E., (Eds.) (in press). White Supremacy and the American Media. Routledge.

Noddings, N. (2005). Global citizenship: Promises and problems. In N. Noddings (Ed.), Educating citizens for global awareness (pp. 1-21). Teachers College.

Nieto, S. (2017). Re-imagining multicultural education: New visions, new possibilities. Multicultural Education Review, 9(1), 1-10. https://doi.org/10.1080/2005615X.2016.1276671.

Oyserman, D., Coon, H. M., \& Kemmelmeier, M. (2002). Rethinking individualism and collectivism: evaluation of theoretical assumptions and meta-analyses. Psychological Bulletin, 128(1), 3-72. https://doi.org/10.1037/00332909.128.1.3.

Powell, R. (1996). Confronting White Hegemony: Implications for Multicultural Education. Multicultural Education, 4(2), 12-15.

Pyle, A. (2013). Engaging young children in research through photo elicitation. Early Child Development and Care, 183(11), 1544-1558. https://doi.org/10.1080/03004430.2012.733944.

Quintana, S. M. (1998). Children's developmental understanding of ethnicity and race. Applied and Preventive Psychology, 7(1), 27-45. https://doi.org/10.1016/S0962-1849(98)80020-6.

Quintana, S. M., Aboud, F. E., Chao, R. K., Contreras-Grau, J., Cross, W. E., Hudley, C., \& Vietze, D. L. (2006). Race, ethnicity, and culture in child development: Contemporary research and future directions. Child Development, 77(5), 1129-1141. https://doi.org/10.1111/j.14678624.2006.00951.x.

Ramasubramanian, S. (2011). Television exposure, model minority portrayals, and Asian-American stereotypes: An exploratory study. Journal of Intercultural Communication, 26(1), 1-17.

Ramsey, P. G. (2015). Teaching and learning in a diverse world: multicultural education for young children (4th ed.). Teachers College Press.

Robinson, T., \& Anderson, C. (2006). Older characters in children's animated television programs: A content analysis of their portrayal. Journal of Broadcasting \& Electronic Media, 50(2), 287-304. https://doi.org/10.1207/s15506878jobem5002_7. 
Roxas, K., Cho, J., Rios, F., Jaime, A., \& Becker, K. (2015). Critical cosmopolitan multicultural education (CCME). Multicultural Education Review, 7(4), 230248. https://doi.org/10.1080/2005615X.2015.1112564.

Sedláková, R. (2006). The media as a tool of social exclusion-an example of presentation of the Roma in the Czech media. In T. Sirovátka (ed.), The challenge of social inclusion: Minorities and marginalized groups in Czech society (pp. 155-181). Barrister \& Principal.

Shaheen, J. G. (2003). Reel Bad Arabs: How Hollywood Vilifies a People. The ANNALS of the American Academy of Political and Social Science, 588(1), 171-193. https://doi.org/10.1177/0002716203588001011

Steele, C. D., Court, D. S., \& Balding, D. J. (2014). Worldwide F(ST) estimates relative to five continental-scale populations. Annals of human genetics, 78(6), 468-477. https://doi.org/10.1111/ahg.12081.

Storm-Mathisen, A. (2016). Grasping children's media practices-theoretical and methodological challenges. Journal of Children and Media, 10(1), 81-89. https://doi.org/10.1080/17482798.2015.1121888.

Todd, S. (2009). Towards an imperfect education: Facing humanity, rethinking cosmopolitanism. Paradigm.

Tuček, M. (2019, April 15). The Czech public's views of ethnic groups living in the Czech Republic [Press release]. Retrieved from http://cvvm.soc.cas.cz/en/press-releases/other/relations-attitudes/4910the-czech-public-s-views-of-ethnic-groups-living-in-the-czech-republicmarch-2019

Tynes, B. M., Seaton, E., \& Zuckerman, A. (2015, December). Online racial discrimination: A growing problem for adolescents. Psychological Science Agenda. Retrieved from http://www.apa.org/science/about /psa/2015/12/online-racial-discrimination.aspx.

Veale, A. (2005) 'Creative methodologies in participatory research with children', In S. Greene \& D. Hogan (eds.), Researching Children's Experience. Approaches and Methods (pp. 253-272). SAGE

Vissers, S., Hooghe, M., Stolle, D., \& Maheo, V. A. (2012). The impact of mobilization media on off-line and online participation: Are mobilization effects medium-specific? Social Science Computer Review, 30(2), 152-169. https://doi.org/10.1177/0894439310396485.

Wall, J. (2019). Theorizing children's global citizenship: Reconstructionism and the politics of deep interdependence. Global Studies of Childhood, 9(1), 5-17. https://doi.org/10.1177/2043610618815484.

Willet, C., \& Willet, J. (2013). Trayvon Martin and the tragedy of the new Jim Crow. In G. Yancy \& J. Jones (Eds.), Pursuing Trayvon Martin: Historical contexts and contemporary manifestation of racial dynamics (pp. 215-224). Lexington Books. 
Woodfall, A., \& Zezulkova, M. (2016). What 'children' experience and 'adults' may overlook: Phenomenological approaches to media practice, education and research. Journal of Children and Media, 10(1), 98-106. https://doi.org/10.1080/17482798.2015.1121889.

Woodfall, A., \& Zezulkova, M. (2019). Children's culture. The International Encyclopedia of Media Literacy, 1-10. https://doi.org/10.1002/ 9781118978238.ieml0020.

Zaal, M. (2012). Islamophobia in classrooms, media, and politics. Journal of Adolescent \& Adult Literacy, 55(6), 555-558. https://doi.org/10.1002/JAAL.00066.

Zehnder, S. M., \& Calvert, S. L. (2004). Between the hero and the shadow: Developmental differences in adolescents' perceptions and understanding of mythic themes in film. Journal of Communication Inquiry, 28(2), 122-137. https://doi.org/10.1177/0196859903261797.

Zezulkova, M. (2015). Media learning in primary school classroom: Following teachers' beliefs and children's interests. In S. Kotilainen \& R. Kupiainen (Eds.), Reflections on Media Education Futures (pp. 159-169). Nordicom \& University of Gothenburg.

\section{Acknowledgment}

This study was supported by the Technological Agency of the Czech Republic, specifically the project TL01000253 Multicultural Life and Learning of Child Prosumers, and by the Charles University Research Programme "Progres" Q18 Social Sciences: From Multidisciplinarity to Interdisciplinarity.

\section{Author Contact}

Markéta Supa, marketa.supa@fsv.cuni.cz Vlastimil Nečas, vlastimil.necas@fsv.cuni.cz Jana Rosenfeldová, jana.rosenfeldova@fsv.cuni.cz Victoria Nainová, victoria.nainova@fsv.cuni.cz Department of Media Studies, Institute of Communication Studies and Journalism, Faculty of Social Sciences, Charles University, Smetanovo nabr. 6, 11001 Prague 1, Czech Republic 